\title{
DE LOS CAMPOS AGRÍCOLAS A LOS CENTROS FINANCIEROS. CARACTERES DE LA INMIGRACIÓN INTERNACIONAL EN PARAGUAY A PRINCIPIOS DEL SIGLO XXI ${ }^{1}$.
}

\section{Sylvain Souchaud}

\section{Introducción}

En este texto se describen las características actuales y la dinámica de la inmigración en Paraguay, insistiendo en las especificidades espaciales de los flujos que, en las últimas décadas, adquirieron una mayor complejidad.

Paraguay ofrece hoy una diversidad migratoria importante que se construyó con base a varios episodios históricos. Después del cierre del territorio nacional que caracteriza los primeros decenios de la era republicana, a partir de la segunda mitad del siglo XIX, el país reorienta su política migratoria de manera radical. El Paraguay abre sus fronteras e incentiva la inmigración internacional. Los llamados tuvieron poco eco, si se compara los flujos de inmigración que en aquella época entraron en Paraguay con los que simultáneamente llegaron a Argentina, Brasil y Uruguay. Después de la Segunda Guerra Mundial se abre una nueva fase en la historia migratoria de Paraguay, cuando llegan al país volúmenes importantes de inmigrantes brasileños, los cuales juntándose con otros flujos hacen del Paraguay actual un país de inmigración importante en el contexto regional.

Creemos que la lectura espacial de la migración, a partir de tres contingentes bastante diferenciados, los nacidos en Argentina, Brasil y Corea, completada con datos sobre las actividades económicas de los migrantes, no solamente nos permitirá percibir la dinámica actual de la inmigración internacional en Paraguay, sino que también nos mostrará algunos aspectos de la importante transición demo-espacial que conoce el país en su actualidad.

Después de una breve reseña de la historia inmigratoria del Paraguay, analizaremos lo que distingue a las tres poblaciones mencionadas en cuanto a su dinámica espacial y sus características laborales actuales. A esta mirada, localizada en el tiempo en el momento del censo de población del 2002, juntaremos una perspectiva temporal que nos permita señalar algunos aspectos de la dinámica de estos grupos de inmigrantes.

\footnotetext{
${ }^{1}$ Una primera versión de este texto fue presentada en las IX Jornadas de Estudios de Población de la AEPA, Huerta Grande, Argentina, octubre 2007.
} 


\section{Generalidades sobre los flujos de inmigración internacional históricos y más recientes en Paraguay.}

La historia migratoria del Paraguay se distingue de la de los demás países de la franja atlántica de América del Sur, aunque, de la misma forma que en los países vecinos, se haya planteado temprano la cuestión de la ocupación del espacio.

El período post-colonial se inicia con la presidencia de José Gaspar Rodríguez de Francia (1811-1840), marcada por el cierre de las fronteras nacionales: la emigración se prohíbe y se llega incluso a expulsar extranjeros. Este paréntesis de casi 30 años es una ruptura completa en la forma de articular el proyecto territorial (primero colonial y luego nacional) con la migración internacional. Recién con Estanislao López y luego su hijo, Francisco Solano López (1840-1970), se comienza a concebir que el aporte migratorio podría formar parte del proyecto nacional, siendo que el poblamiento no solamente es una condición para la explotación de los recursos y el crecimiento económico, sino que también es factor de consolidación del poder central, el cual, estimulando y acompañando la ocupación de espacios marginales y/o periféricos amplía y refuerza el anclaje del territorio nacional. Las primeras colonias extranjeras se forman, modesta y poco exitosamente, con el apoyo (discontinuo) del Estado. Es así que a mediados del siglo XIX, Paraguay sigue siendo un país con bajísima densidad poblacional que además cuenta con importantes desequilibrios en la repartición de la población.

La guerra contra la Triple Alianza (1864-1870) acelera el desajuste entre la población y su territorio al disminuir drásticamente la población total y cambiar su estructura. Así, se estima que el Paraguay contaba tan sólo con aproximadamente 300.000 habitantes en 1870, en su gran mayoría mujeres. Es más, la profunda crisis que se inicia, económica y luego política, alimenta también una fuerte emigración hacia Argentina y Brasil principalmente.

En el último cuarto del siglo XIX, Paraguay registraba una densidad demográfica de aproximadamente $1 \mathrm{hab} . / \mathrm{Km}^{2}$, y esto aún antes de ampliarse el territorio paraguayo con una parte sustantiva del Chaco boliviano (Guerra del Chaco 1932-1935). La dificultad de ocupar y valorizar el territorio nacional, debido a la escasez de fuerza laboral y de inversores nacionales, lleva al poder político a concebir un proyecto nacional en asociación con una apertura amplia del territorio del país a la inmigración y a los capitales extranjeros. De hecho, la penetración argentina y brasileña se produce también como consecuencia directa de la Guerra contra la Triple Alianza. El Estado paraguayo, muy debilitado, debe ceder a las presiones de los actores económicos extranjeros.

En esta época, grandes extensiones de tierra se venden a empresas o latifundiarios extranjeros, principalmente argentinos y brasileños, y por primera vez, se privatiza una parte substantiva de las tierras agrícolas ${ }^{2}$. Por otra parte se relaciona, explícitamente el desarrollo nacional al desarrollo de la actividad rural y agrícola, lo cual se realizará con aportes

\footnotetext{
${ }^{2}$ Recordemos que J. Rodríguez de Francia se lanzó a la nacionalización de las tierras (que pertenecían principalmente a la iglesia y a la oligarquía criolla) y ejercitó un fuerte control en la distribución de las tierras fiscales.
} 
significativos de colonos extranjeros (Pidoux de Drachenberg 1975). Así, comienza una política nacional de promoción de la inmigración regida a partir de 1872 por el Departamento General de Inmigración y en 1881, fue promulgada la primera Ley de Inmigración y Colonización (Fischer, Palau y Noemia 1997).

A pesar de los beneficios ofrecidos a los inmigrantes internacionales, Paraguay resultó poco atractivo en comparación con lo que ocurrió en Brasil, Argentina y Uruguay (Bassanezi s.d.; Celton 1995). Entre 1900 y 1930 entraron en Paraguay 18.606 personas de las cuales 6.486 eran agricultores. Junto con la inmigración de argentinos, italianos y españoles, otras dos poblaciones se destacan ligeramente. Por un lado, a partir de 1921 empiezan a llegar los menonitas a los cuales se otorgó la libertad de culto y de mantener un sistema de educación en su idioma y la exención impositiva por 10 años. Por otro, en 1919, se firma un Tratado de Comercio entre Paraguay y Japón y comienza la inmigración japonesa que será limitada a las colonias agrícolas (La Colmena por ejemplo) y en 1939 vivían 622 japoneses en Paraguay.

La década del 30 tendrá el mayor flujo de entrada de inmigrantes del período considerado: 20.141 personas (Fischer, Palau, and Noemia 1997), lo que parece muy poco a pesar de que correspondía al $2 \%$ de la población total.

De las 53.212 personas que inmigraron entre 1870 y 1960 , y para citar los principales orígenes, se cuentan 9.188 argentinos, 6.522 menonitas $^{3}, 4.804$ japoneses, 4.467 alemanes, 4.189 españoles y 4.059 italianos. (Fischer, Palau, and Noemia 1997, p. 9)

La inmigración, hasta la década del sesenta, nunca fue importante en valores absolutos, pero existía tanto una voluntad política de fomento de la inmigración internacional, principalmente ultramarina, como cierta tradición de hospitalidad en Paraguay. Y considerando la proporción de extranjeros sobre la población total, la inmigración en Paraguay no resulta en absoluto despreciable en aquella época. Cabe mencionar que la inmigración menonita, aunque numéricamente modesta, resultó ser un proceso exitoso para el desarrollo de Paraguay si se considera el dinamismo económico actual de las colonias (sobre todo del Chaco) que tienen una proyección nacional e internacional.

A partir de los años 60, la inmigración adquiere nuevas características. Primero se va a intensificar, tanto absoluta como relativamente, y a diversificar su distribución espacial, instalándose tanto en las periferias rurales como en los centros urbanos. De tal forma que Paraguay mantiene y confirma su perfil emigratorio (a Argentina principalmente) pero también se vuelve país de inmigración; situación novedosa en la región. Ya lo hemos dicho, Paraguay no tiene una fuerte tradición inmigratoria de ultramar, lo cual dejó de ser importante en toda América latina a partir de los años 70, pero al mismo tiempo, se intensificó la inmigración latinoamericana. En este nuevo patrón migratorio regional, Paraguay viene a asumir un nuevo papel: se vuelve país de inmigración (Tabla 1). Tanto que a pesar de ser un país poco poblado, va a identificarse, a principio de los años 70, como cuarto país (después de Argentina, Venezuela y Brasil) en América latina por el volumen

${ }^{3}$ Consideramos abusivamente a los menonitas como a una nacionalidad, solamente para facilitar la identificación de esta población y flujo de inmigrantes tan específico. 
de inmigrantes latinoamericanos, y tercer país de inmigración a principio de los años 1980 y 1990 (después de Argentina y Venezuela).

Tabla 1

Población residente en el Paraguay nacida en América latina, 1972-2002

\begin{tabular}{|l|c|c|c|c|}
\hline & $\mathbf{1 9 9 2}$ & $\mathbf{1 9 7 2}$ & $\mathbf{1 9 8 2}$ & $\mathbf{2 0 0 2}$ \\
\hline Total América latina & 63.797 & 149.940 & 166.380 & 155.938 \\
Total & - & 168.104 & 190.729 & 173.176 \\
\hline
\end{tabular}

Fuente: Censo de Población, 1982,1991, 2002, DGEEC, Asunción y IMILA Elaboración propia

En 2002, la población nacida en el exterior y censada alcanzaba 173.176 personas, lo que corresponde a 3,3\% de la población total del país. Nuevamente Paraguay afirma su carácter de país de inmigración, mucho más que Brasil por ejemplo, cuya población nacida en el exterior y censada representaba $0,3 \%$ de la población total en 2000. Mirando más de cerca la composición de la inmigración en Paraguay en 2002 (Tabla 2), vemos que los primeros contingentes son los brasileños (81.592), luego los argentinos (63.153), los uruguayos (3.239) y los coreanos (2.822). Constatamos también que de los diez primeros países que alimentan flujos de población hacia Paraguay, uno solo es europeo (Alemania), dos son asiáticos (Corea y Japón) y los demás son latino-americanos ${ }^{4}$.

Tabla 2

Población nacida en el exterior y residente en Paraguay según los 10 principales países de nacimiento en 2002

\begin{tabular}{|l|r|r|}
\hline País & \multicolumn{1}{|c|}{ EF. } & \% del total \\
\hline Brasil & 81.529 & 47,1 \\
Argentina & 63.153 & 36,5 \\
Uruguay & 3.239 & 1,9 \\
Corea & 2.822 & 1,6 \\
Chile & 2.336 & 1,3 \\
Japón & 2.197 & 1,3 \\
Alemania & 1.838 & 1,1 \\
México & 1.778 & 1,0 \\
Estados Unidos & 1.747 & 1,0 \\
Perú & 1.621 & 0,9 \\
Sub Total & 161.323 & 93,7 \\
Total & $\mathbf{1 7 3 . 1 7 6}$ & $\mathbf{1 0 0 , 0}$ \\
\hline
\end{tabular}

Fuente: Censo de Población 2002, DGEEC, Asunción . Elaboración propia

\footnotetext{
${ }^{4}$ Parecerá sorprendente la presencia de mejicanos, son probablemente menonitas.
} 


\section{Distribución y dinámica espacial de la población del Paraguay y de los inmigrantes internacionales.}

Privilegiamos en este trabajo el estudio de tres contingentes de inmigrantes internacionales: los brasileños, los argentinos y los coreanos, cuyas características y modalidades nos parecen ilustrar la variedad de los procesos socio-espaciales en curso en el Paraguay contemporáneo.

Antes de presentar la distribución espacial de los inmigrantes, hay que considerar algunos aspectos de la geografía de la población paraguaya en su totalidad, que tienen influencia sobre la primera.

En primer término, el Mapa 1, representando la distribución espacial de los paraguayos en el territorio en 2002, muestra un profundo desequilibrio en la ocupación del espacio. La gran mitad occidental del territorio, el Chaco, en la margen derecha del río Paraguay, se encuentra despoblada, contando sólo con 135.186 habitantes lo que representa 2,6\% de la población total del país. En 2002 entonces, se confirma, por lo menos a nivel demográfico, la tendencia histórica de marginalización del Chaco. Si bien en el pasado se invocaba el medio natural (Souchaud 2007), y principalmente la cuestión de los recursos hídricos, para explicar la dificultades de ocupación humana en el Chaco, habría hoy que relativizar este hecho y quizá considerar, por ejemplo, las consecuencias de una política territorial nacional que siempre privilegió el Oriente (infraestructuras, colonización por ejemplo) hasta que hoy día los retrasos acumulados del Chaco alimentan por sí solos su propia marginalización.

En segundo lugar, el Mapa 1 muestra una ocupación bastante homogénea de la región oriental que concentra más del 97\% de la población, 5.028.012 habitantes en 2002. Esto representa una condición relativamente reciente ya que los anteriores mapas de distribución de la población, según los censos, mostraban espacios vacíos dentro la región oriental o, mejor dicho, discontinuidades importantes en la ocupación. Desde el censo de 1992, casi todos los distritos paraguayos conocieron un importante crecimiento demográfico.

En tercer lugar, a pesar de la relativa homogeneidad de la distribución poblacional en la región oriental, se puede identificar un eje de mayor densidad poblacional orientado oeste-este en el centro, que se extiende entre Asunción y Ciudad del Este, y se observa sobre todo la concentración más importante en Asunción y su vecindad. Lo interesante es que no se reproduce tal impresión de concentración en otro lugar de la región oriental, lo que implica que ninguna ciudad tiene una importancia semejante a la de Asunción. Este hecho se presenta como una continuidad en el modelo territorial paraguayo de larga data, marcado por la macrocefalia urbana asunceña. Obviamente, Ciudad del Este aparece como un contrapeso, pero todavía muy débil frente al área metropolitana de Asunción (Causarano 2006), que sigue ganando población entre los últimos dos censos.

Esos tres elementos: vacío chaqueño, concentración y homogeneidad oriental y primacía asunceña van, de manera aislada o conjunta, a encontrarse en la dinámica de distribución espacial de los contingentes inmigrantes. 


\section{Mapa 1}

Población Paraguaya según distritos, en 2002

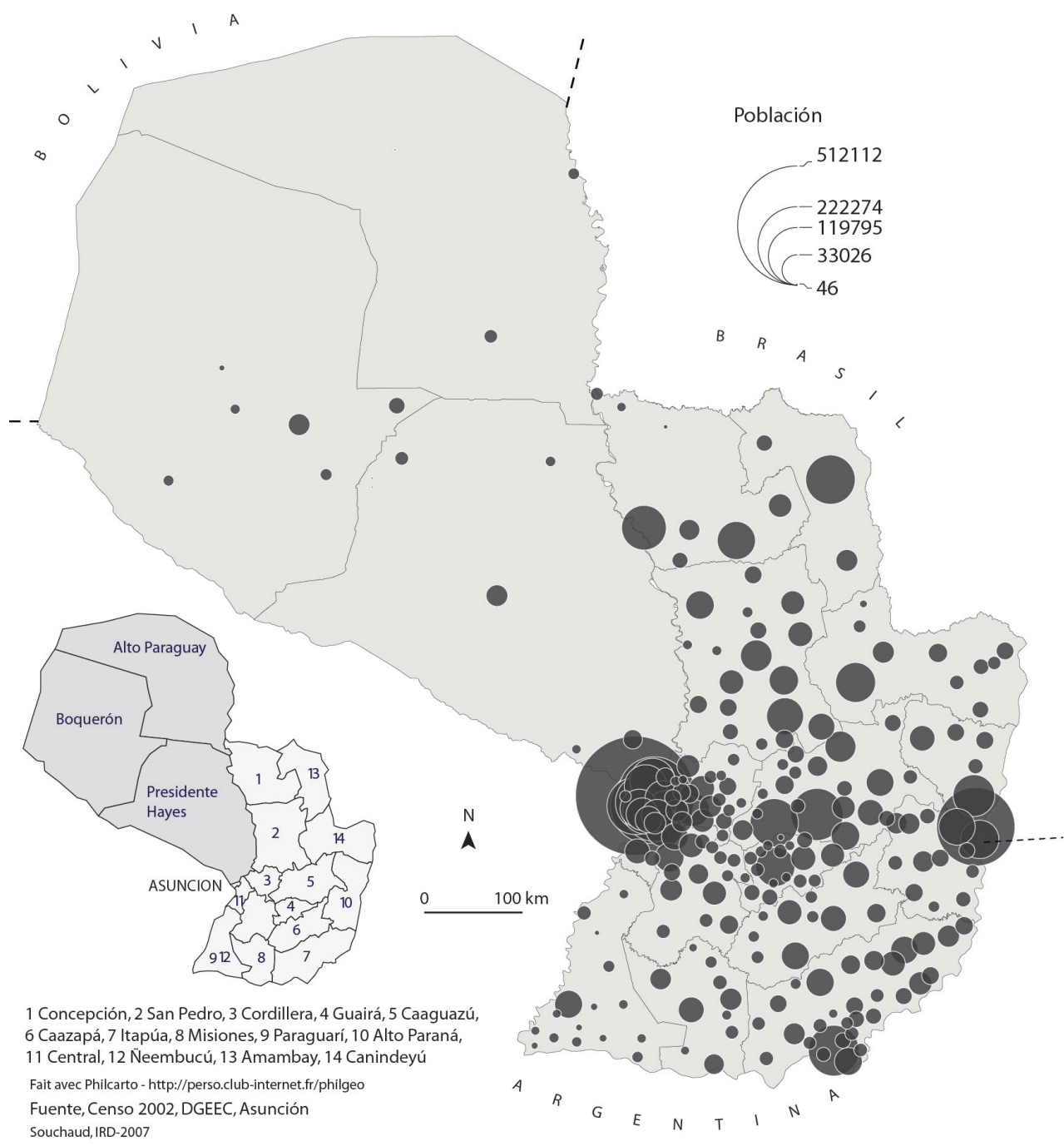

Nos detendremos primero en los dos mapas de localización de los contingentes argentinos, brasileños y coreanos. Debido al hecho de que los coreanos son mucho menos numerosos, los representamos en un mapa (Mapa 3) distinto de aquel en donde figuran los inmigrantes brasileños y argentinos (Mapa 2), debido a la necesidad de usar una escala numérica distinta para representar sus respectivos volúmenes de población. Observamos 
nítidamente una distribución espacial muy diferente y poco coincidente entre los argentinos y los brasileños. Los dos contingentes "sienten" una fuerte atracción hacia las áreas de frontera de su propio país de origen. Pero, dentro de este tropismo, aparece otro que es la polarización urbana para los argentinos y la polarización rural para los brasileños. Eso está bastante claro para los argentinos concentrados en su mayoría en la metrópolis de Asunción y de manera secundaria en Encarnación, ciudad que está frente a Posadas en Argentina. Esta distribución de la inmigración argentina (re)produce el antiguo eje de integración del territorio paraguayo (Souchaud 2007; Vázquez 2006), que quedó vigente desde los primeros tiempos de la época colonial hasta mediados del siglo XX. Es interesante insistir en el hecho de que si los argentinos sienten una atracción por las ciudades, siguen algunos criterios que no solamente dependen del tamaño y dinamismo económico. Así, Ciudad del Este, segundo polo urbano del país e importante centro económico y financiero, cuenta con muy pocos argentinos.

\section{Mapa 2}

\section{Población nacida en Argentina y en Brasil según distritos de residencia en 2002}

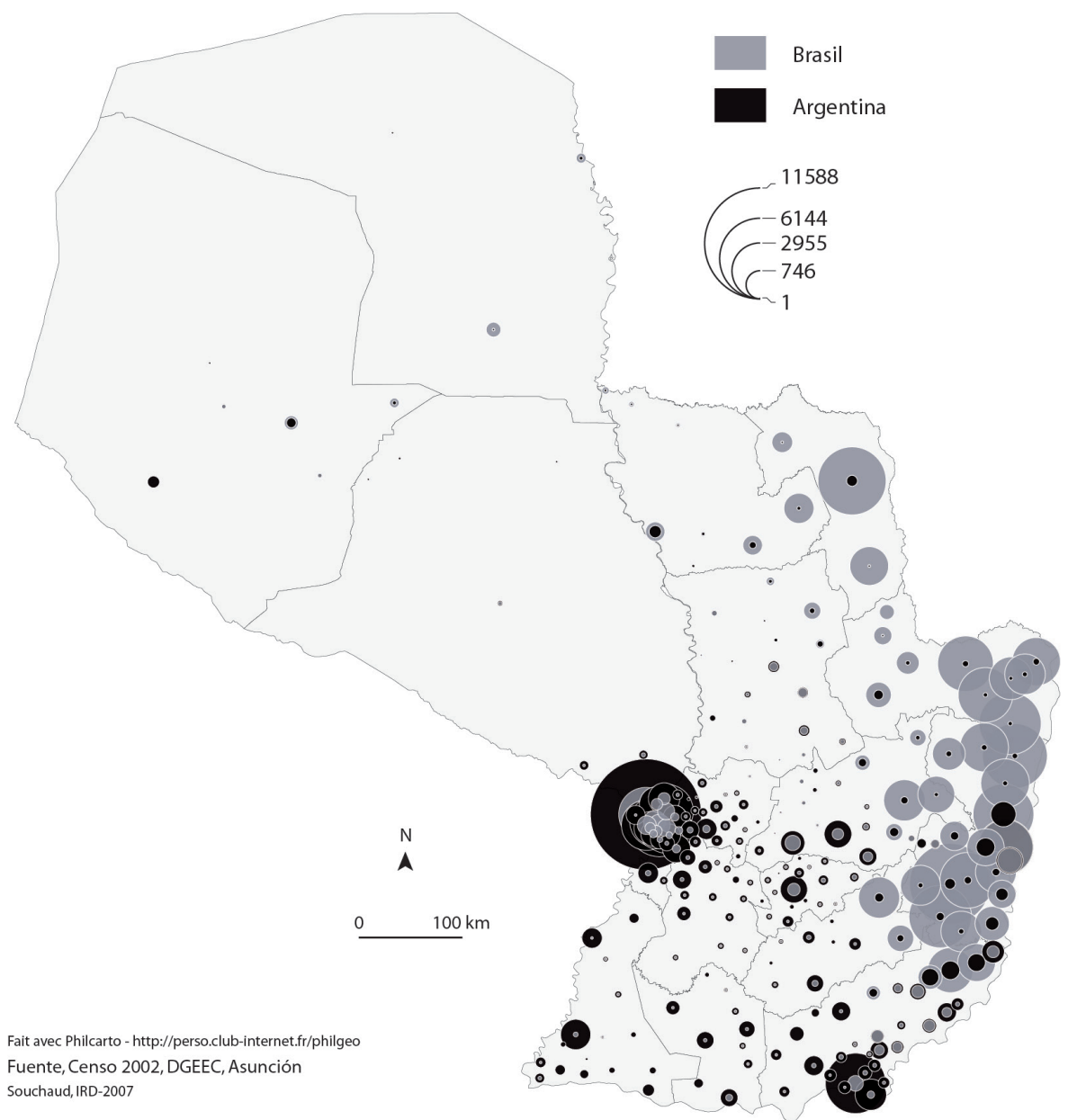




\section{Mapa 3}

Población en Corea según distritos de residencia en 2002

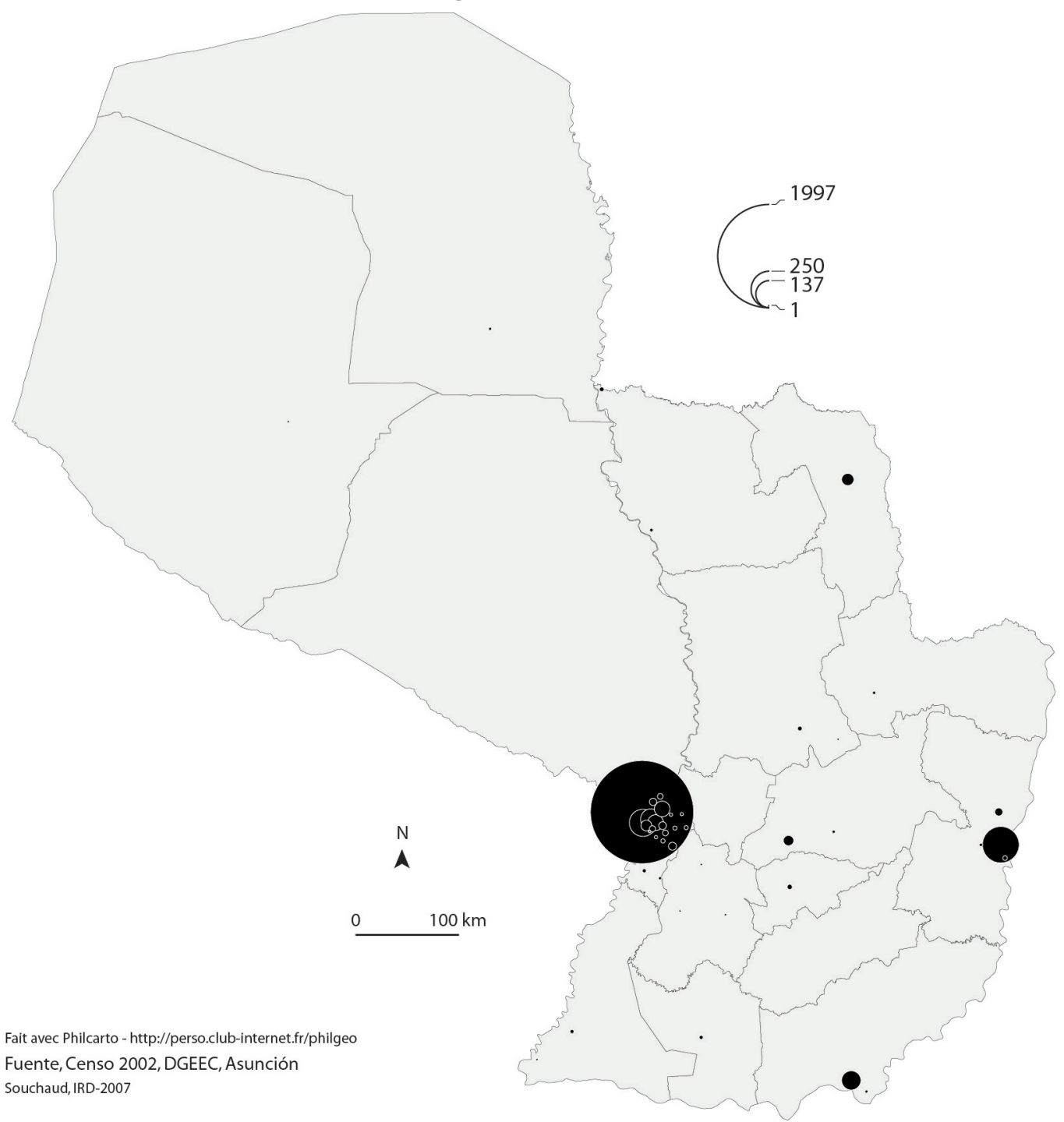

La atracción del rural para los brasileños no aparece claramente en el Mapa 2, pero es un elemento esencial al entendimiento de la dinámica migratoria brasileña. Este hecho se verifica en la Tabla 3 donde se examina los tipos de lugares de residencia de los inmigrantes. Notamos que los brasileños son claramente rurales cuando los argentinos son, en su gran mayoría, urbanos y los coreanos casi exclusivamente urbanos. Podríamos relativizar esta información, al recordar que los inmigrantes internacionales residen predominantemente en las ciudades, hecho común entre los países de inmigración que se verifica también en Paraguay. Pero podemos señalar que los inmigrantes argentinos son más urbanos que la 
población total paraguaya y que la población inmigrante total, el $60,1 \%$ de la cual reside el áreas urbanas, pero bastante menos que varios colectivos inmigrantes, como los coreanos que se ubican en poquísimos lugares y se concentran esencialmente en Asunción. Muestran también una presencia relativamente importante en Ciudad del Este y de manera residual, aparecen en Encarnación, Coronel Oviedo y Pedro Juan Caballero.

Tabla 3

Población residente en el Paraguay nacida en América latina, 1972-2002

\begin{tabular}{|l|l|l|l|l|}
\hline & Argentina & Brasil & Corea & país \\
\hline Urbana & $80,0 \%$ & $38,2 \%$ & $98,4 \%$ & $58,4 \%$ \\
Rural & $20,0 \%$ & $61,8 \%$ & $1,6 \%$ & $41,6 \%$ \\
Total & $100,0 \%$ & $100,0 \%$ & $100,0 \%$ & $100,0 \%$ \\
\hline
\end{tabular}

Fuente: Censo de Población 2002, DGEEC, Asunción Elaboración propia

A continuación consideraremos el impacto demográfico local de cada nacionalidad. Los argentinos, como vimos, están muy presentes en toda el área de frontera, desde el Chaco occidental hasta el río Iguazú, pero su presencia no llega a ser importante en términos relativos. Solamente en un distrito del Chaco (Nanawa) donde la presencia humana es escasa, los argentinos alcanzan un peso máximo del 7,2\% de la población total del distrito. En el $90 \%$ de los distritos de Paraguay, los inmigrantes argentinos representan menos del $2,0 \%$ de la población total del distrito.

La situación es muy distinta en el caso de los inmigrantes brasileños. Su presencia puede alcanzar el 37,6\% de la población total de un distrito, como en el caso extremo del distrito de Katueté en el departamento de Canindeyú. Igualmente, el 10\% de los distritos paraguayos concentran relativamente más población inmigrante de Brasil, que llega a representar el 10,0\% o más de la población total.

Esa presencia importante en numerosos distritos del Oriente se observa principalmente en Alto Paraná y Canindeyú (Mapa 4) y, es importante insistir en este aspecto, en distritos que no son en absoluto jurisdicciones vacías. Sabemos, por otra parte (Palau y Heikel 1987; Souchaud 2007), que esos distritos estaban escasamente ocupados con anterioridad a la llegada de los brasileños. De modo que aparece claramente una diferencia entre la inmigración brasileña y la argentina: la primera asume un papel poblador (colonizador) al contrario de la segunda. Obviamente, este hecho habría que confirmarlo con el estudio de varios elementos y en particular la dimensión histórica de cada migración, a nivel individual y colectivo. La migración argentina, en aumento reciente, alcanzó su más alto valor en el censo 2002, y es cierto que hasta ahora no ha tenido el mismo potencial demográfico que registra la inmigración brasileña. Pero también abría que considerar el "proyecto" migratorio, o sea como cada flujo se especializa en un sector de actividad o en 
un determinado tipo de territorio, y cómo esas particularidades influyen diferenciadamente en la dinámica territorial y cuál es su potencial polarizador o sea, como puede un flujo migratorio, en el caso internacional, inducir a su vez una migración interna.

De la observación de la distribución espacial de la inmigración argentina, brasileña y coreana, recordaremos las diferencias nítidas entre el modelo argentino y brasileño que casi no se cruzan en el espacio y, a pesar de elementos coincidentes entre la ocupación coreana y argentina, notamos una diferencia importante en la común atracción urbana: para los coreanos prevalecen aparentemente los centros económicos, en cuanto que para los argentinos el modelo es más complejo.

\section{Mapa 4}

\section{Población nacida en Brasil, en volumen y en proporción} de la población total del distrito, en 2002

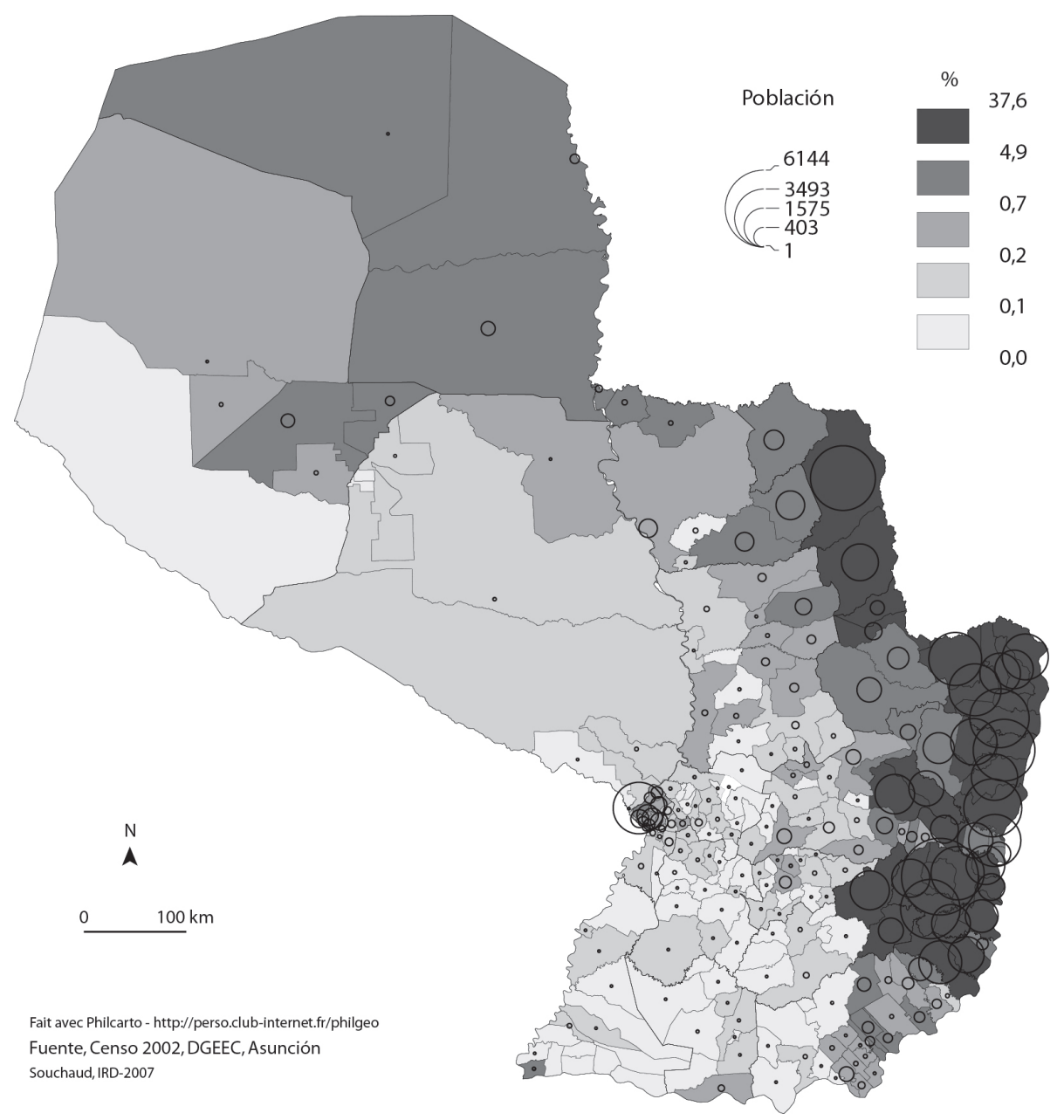


Y finalmente, la superposición de estos diferentes modelos compone un cuadro bastante equilibrado, o por lo menos, coherente con lo que observamos al inicio referente a los padrones de la repartición de la población paraguaya.

\section{Actividad económica de los inmigrantes}

Las actividades económicas de los inmigrantes internacionales en Paraguay se distinguen en función de su origen y explican en parte la distribución espacial diferenciada.

El primer elemento que aparece de manera clara es la especialización brasileña en las actividades agrícolas (Tabla 4). La mitad de los inmigrantes económicamente activos de esta nacionalidad trabajan en el sector primario, lo que explica la importancia de lo rural en cuanto a los tipos de lugares de residencia. La fuerte especialización de los brasileños es característica de una forma de migración relacionada a la extensión de la frontera agrícola. No volveremos sobre este punto (Souchaud 2007), pero cabe insistir en el hecho de que no todos los brasileños son agricultores, y no todos los agricultores son empresarios del sector agro-exportador especializado en la producción de soja. No se dispone de un censo agropecuario reciente, $\mathrm{y}$, obviamente, el censo de población de 2002 no permite distinguir los tipos de rubros agrícolas producidos. De todas maneras, el censo informa que el 6,4\% de los activos nacidos en Brasil son "mozos de labranza y peones agropecuarios". Esto indica claramente que existen otros tipos de producción y relaciones laborales en el "agro brasileño" en el Paraguay, ya que los mozos y peones son empleados poco cualificados y con bajo nivel de ingreso y que los segundos apuntan a un sector de actividad importante para la población inmigrante brasileña: la ganadería. Aún cuando es cierto que, en muchos espacios, la soja impone un modelo hegemónico de monocultivo intensivo, empresarial y familiar, todavía existen otras formas de producir y otros productos en el sector agrícola.

Por otro lado, es interesante ver que, si prevalece la residencia rural y las actividades rurales en la población de origen brasileño, también hay una población inmigrante importante que vive en la ciudad y que se dedicada a otro tipo de actividades, comerciales y de servicios. Entre estas últimas, se destacan las empleadas domésticas que representan el $7,0 \%$ del total de los activos empleados en 2002 (Tabla 4). Esa migración poco cualificada, urbana, con bajos rendimientos salariales es una faceta importante, aunque poco visible de la migración brasileña en Paraguay, que habíamos mencionado años atrás, sin cuantificarla.

En lo que se refiere a los inmigrantes oriundos de Argentina, los perfiles laborales son aún más diversificados y realmente no aparece una sola especialización. Esa diversidad habría que confrontarla con el hecho de que, probablemente, una parte importante de esa migración corresponde al retorno de descendientes de emigrantes paraguayos a Argentina. Esto indicaría que esta migración no es solamente laboral y relacionada a una especialización u oportunidad sectorial (un "nicho" ocupacional), al igual que la agricultura para los brasileños, y que el comercio de electrónicos para los coreanos. La migración sería en este caso algo más "étnico", lo que explicaría que sea más diversificada, ya sea en su distribución espacial, como en sus perfiles socio-ocupacionales. 
Tabla 4

Población nacida en el exterior por país de nacimiento y sector de actividad en 2002

\begin{tabular}{|c|c|c|c|c|c|c|}
\hline & \multicolumn{2}{|c|}{ Argentina } & \multicolumn{2}{|c|}{ Brasil } & \multicolumn{2}{|c|}{ Corea } \\
\hline & Ef. & $\%$ & Ef. & $\%$ & Ef. & $\%$ \\
\hline Agricultura, ganadería, caza y silvicultura & 2.137 & 7,2 & 22.715 & 49,8 & 22 & 1,2 \\
\hline Pescas y servicios conexos & 95 & 0,3 & 32 & 0,1 & 0 & 0,0 \\
\hline Explotación de minas y canteras & 14 & 0,0 & 13 & 0,0 & 0 & 0,0 \\
\hline Industrias manufactureras & 3.607 & 12,2 & 4.117 & 9,0 & 159 & 8,5 \\
\hline Electricidad, gas y agua & 95 & 0,3 & 31 & 0,1 & 1 & 0,1 \\
\hline Construcción & 1.968 & 6,6 & 2.008 & 4,4 & 3 & 0,2 \\
\hline $\begin{array}{l}\text { Comercio al por mayor y menor, reparación } \\
\text { de vehículos automotores, motocicletas, } \\
\text { afectos personales y enseres domésticos }\end{array}$ & 8.208 & 27,7 & 7.147 & 15,7 & 1.316 & 70,0 \\
\hline Servicios de hotelería y restaurantes & 1.027 & 3,5 & 822 & 1,8 & 65 & 3,5 \\
\hline $\begin{array}{l}\text { Servicio de transporte, de almacenamiento y } \\
\text { de comunicaciones }\end{array}$ & 1.561 & 5,3 & 1.990 & 4,4 & 22 & 1,2 \\
\hline $\begin{array}{l}\text { Intermediación financiera y otros servicios } \\
\text { financieros }\end{array}$ & 538 & 1,8 & 147 & 0,3 & 11 & 0,6 \\
\hline $\begin{array}{l}\text { Servicos inmobiliarios, empresariales y de } \\
\text { alquiler }\end{array}$ & 1.803 & 6,1 & 509 & 1,1 & 54 & 2,9 \\
\hline $\begin{array}{l}\text { Administración pública, defensa y seguridad } \\
\text { social obligatoria }\end{array}$ & 958 & 3,2 & 277 & 0,6 & 8 & 0,4 \\
\hline Enseñanza & 1.917 & 6,5 & 473 & 1,0 & 70 & 3,7 \\
\hline Servicios sociales y de salud & 1.107 & 3,7 & 449 & 1,0 & 47 & 2,5 \\
\hline $\begin{array}{l}\text { Servicios comunitarios, sociales y personales } \\
\text { N.C.P. }\end{array}$ & 1.801 & 6,1 & 1.041 & 2,3 & 68 & 3,6 \\
\hline $\begin{array}{l}\text { Servicios de hogares privados que contratan } \\
\text { servicio doméstico }\end{array}$ & 1.744 & 5,9 & 3.185 & 7,0 & 3 & 0,2 \\
\hline $\begin{array}{l}\text { Servicios de organizaciones y órganos } \\
\text { extraterritoriales }\end{array}$ & 43 & 0,1 & 54 & 0,1 & 10 & 0,5 \\
\hline No informado & 1.030 & 3,5 & 595 & 1,3 & 20 & 1,1 \\
\hline Total activos ocupados & 29.653 & 100,0 & 45.605 & 100,0 & 1.879 & 100,0 \\
\hline
\end{tabular}

Fuente: Censo de población 2002, DGGE, Asunción

Elaboración propia

Nuevamente, como en el caso de la inmigración brasileña, encontramos una proporción importante de trabajadores doméstico/as, este aspecto reforzaría la originalidad de la migración argentina en Paraguay comparada a lo que es en los países vecinos, donde se caracteriza por su nivel de calificación, o, simplemente confirmaría la posibilidad que esta migración se compone de un importante retorno escondido por el modo estadístico de tratar la migración. 
Por último, el examen de la inmigración coreana muestra que para la migración de larga distancia, el aspecto laboral sigue siendo un parámetro central para su entendimiento. Vemos que el $70,0 \%$ de los coreanos activos son comerciantes (probablemente en el rubro de los electrónicos). Otro elemento llama la atención, es la participación del 8,5\% de los activos en la actividad industrial manufacturera. ¿Será una actividad relacionada a la confección textil, al igual que lo que ocurre en Buenos Aires y San Pablo por ejemplo? Finalmente, la presencia en "servicios inmobiliarios, empresariales y de alquiler" y en la "enseñanza" puede ser entendida como la existencia actual o la continuación de un servicio comunitario: Quizás se han desarrollado estas actividades como consecuencia de las demandas específicas; es decir, nacieron con la inmigración internacional de coterráneos; la propia inmigración llama a demandas específicas (educación, vivienda,...) a las que los propios inmigrantes saben mejor como satisfacer.

De cierta forma el examen de las ocupaciones de los inmigrantes corrobora especificidades que aparecieron en el análisis de la distribución espacial de los contingentes inmigrantes. Los brasileños alimentan una dinámica agrícola de tipo pionera en las periferias orientales del territorio nacional que se construye alrededor principalmente de la actividad agropecuaria, pero que también contribuye al desarrollo de actividades de servicios e comercio. Los argentinos tienen una diversificación importante de sus actividades, de la misma forma que demostraban una distribución muy específicamente urbana o rural. Los coreanos demuestran un tropismo muy marcado por la ciudades centrales del país, Asunción, la capital y Ciudad del Este, centros financieros y comerciales (Ciudad del Este es zona franca) que concentran, a nivel nacional, el comercio de productos electrónicos e informáticos importados.

\section{Los tiempos de la migración.}

Considerar los flujos desde una perspectiva temporal puede ayudarnos a entender la estructuración de cada flujo y su dinámica actual. Para tal objetivo, podemos utilizar el tiempo de residencia de los migrantes y las pirámides de edades correspondientes a cada contingente.

En la Fig. 1 vemos que hasta el final de los años 1960 la inmigración brasileña y la argentina se presentaban con niveles muy bajos; esto ilustra la tendencia general de aquel entonces cuando el país mantenía una atracción moderada y Paraguay no había entrado en una fase de fuerte inmigración. Las cosas cambian a partir de los primeros años de la década de 1970, cuando se intensifica fuertemente la inmigración brasileña que adquiere un nivel altísimo, nivel que se mantendrá mas o menos estable hasta 1989, fecha del final de la dictadura del general Stroessner y el inicio del proceso de democratización del Paraguay. Sabemos que los últimos años de la dictadura fueron años difíciles para los "brasiguayos"; muchos de ellos fueron expulsados ${ }^{6}$ de Paraguay y los conflictos se agudizaron en los primeros años de la década de los 90 (Cortêz 1993; Wagner 1990). Un nuevo debilitamiento

\footnotetext{
${ }^{6}$ Sobre este aspecto, recordamos el episodio del asentamiento de numerosos brasiguayos al otro lado de la frontera, en Mundo Novo, Mato Grosso del Sur, Brasil. (Cortêz, 1993).
} 
de la inmigración se nota a partir de los años 94-95, que puede explicarse por la estabilidad y el crecimiento económico que trajo el "plan real" en Brasil, puesto en marcha por el entonces ministro brasileño de Hacienda, Fernando Henrique Cardoso, durante la presidencia de Itomar Franco, el cual logró que se reduzca la propensión a emigrar hacia Paraguay.

Gráfico 1: Población residente en Paraguay nacida en Argentina y Brasil y Corea según año de llegada, en 2002.

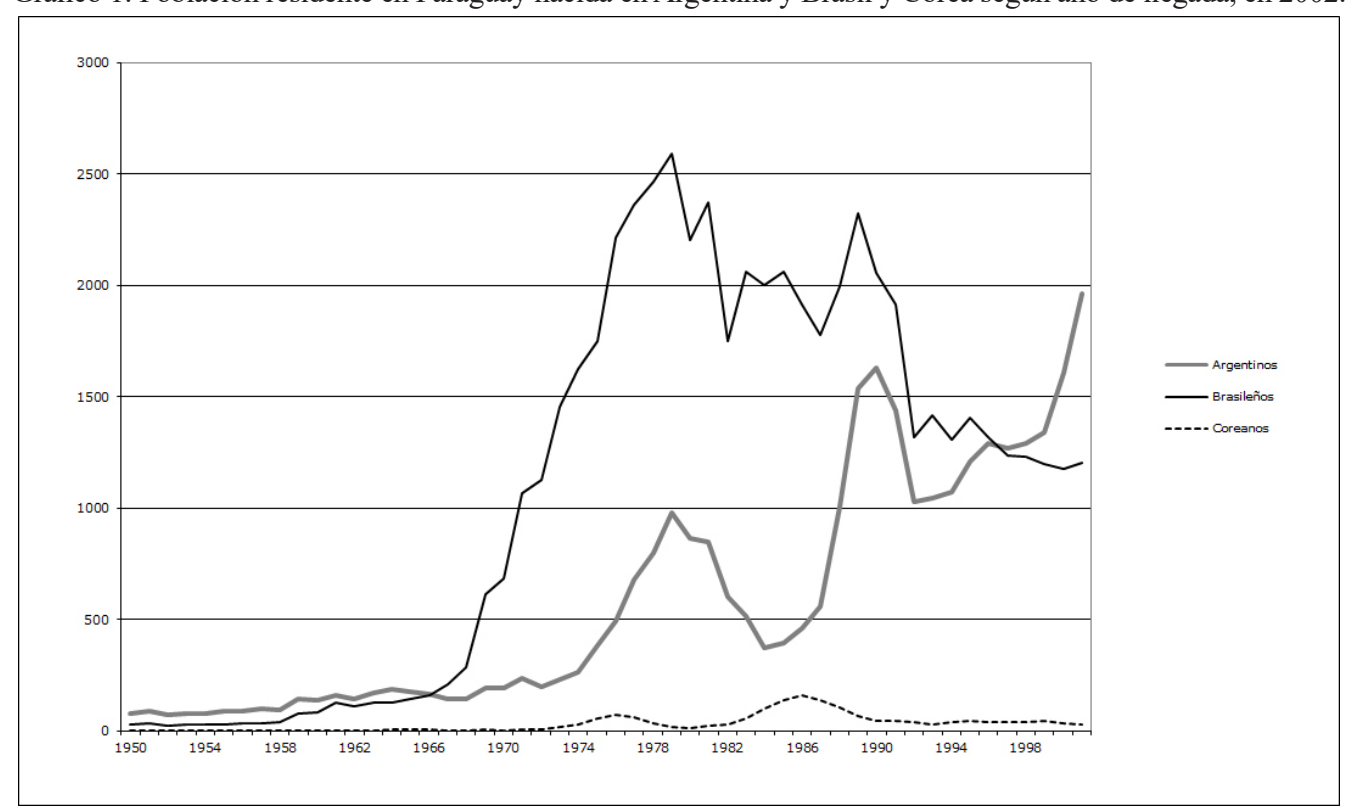

Fuente: Censo de Población 2002, DGEEC, Asunción

Elaboración propia

No disponemos de mucha información para explicar las variaciones de la inmigración argentina en Paraguay y, por supuesto, habría que interesarse por la reciente historia económica y social de Argentina para poder entender el comportamiento emigratorio de las últimas décadas. Pero también habría que interesarse por las oscilaciones de la inmigración paraguaya en Argentina si es que, como lo creemos, el crecimiento de la inmigración argentina en este país está relacionado con el retorno de los inmigrantes paraguayos y sus descendientes. Lo que aparece, es un crecimiento importante de la inmigración argentina, a partir de la década del 1970, pero a la vez más tardío e irregular que el brasileño. Lo interesante es que las curvas de flujos se han cruzado en 1995, y desde entonces el flujo argentino es mayor que el brasileño, y si los volúmenes de inmigrantes brasileños siguen superiores a los de argentinos, eso tiende también a revertirse. O sea, la capacidad de atracción del Paraguay es muy variable según cual país de salida se considere.

En lo que se refiere al flujo coreano, sería importante identificar las etapas del crecimiento de las actividades comerciales en Paraguay, principalmente las relacionadas con el desarrollo del comercio internacional de reexportación (productos variados importados de Asia) y con la formación y el crecimiento de zonas francas comerciales (Ciudad del Este). También sería importante investigar las actividades del sector de la 
confección textil como lo sugerimos anteriormente. Lo que sí aparece claramente en el gráfico es el agotamiento de la migración coreana que alcanzó su auge en 1975 y 1985.

La antigüedad y el relativo estancamiento de la inmigración brasileña se perciben en dos variables del último Censo. En el 2002, la edad media de los inmigrantes brasileños era de 35,3 años; la de los coreanos de 42,1 años. Además, el 10,9\% y el 12,4\% respectivamente, de los inmigrantes brasileños y coreanos eran inmigrantes recientes en 2002, o sea que se habían radicado en Paraguay en los cinco años anteriores a la fecha del Censo (entre agosto del 1997 y 2002). Estos elementos adquieren más significación si se comparan con los de los inmigrantes argentinos cuya edad media se establecía a 27,9 años en el 2002, cuando el 22,6\% eran inmigrantes recientes. De la misma forma, podemos mencionar que en el Censo 1992, el 22,6\% de los inmigrantes de Brasil eran inmigrantes recientes.

Las diferencias de estructuras de las tres poblaciones inmigrantes se observan en las respectivas pirámides de edades (Figs. 3 y 4 ) las cuales también deben compararse son las pirámides de la Fig. 2.

La población inmigrante de Brasil disminuye entre los dos últimos Censos, pero surge una pregunta: ¿el contingente de inmigrantes de Brasil disminuiría sin renovarse o este movimiento de retractación se acompañaría de un intenso movimiento de llegada? Sabemos que la edad media de los inmigrantes de Brasil pasó de 28,8 a 35,3 entre 1992 y 2002. Las pirámides de edades, en dichos años, de los inmigrantes brasileños también nos muestran el envejecimiento de la población inmigrante de Brasil. Este envejecimiento de 6,5 años en 10 años significaría que la población no se renovó marcadamente. A no ser que en el lapso hayan inmigrado individuos más viejos. Ese no es el caso ya que los inmigrantes recientes tenían una edad media de 29,1 años en el 2002 y contando que llegaron con hasta 5 años menos de edad.

Particularmente para el caso de la inmigración brasilera, interrogamos los microdatos del censo 2002 cruzando el sector de actividad según años de llegada para ver si con el tiempo la agricultura perdía su importancia entre los inmigrantes de Brasil. En efecto, se verifica que entre los 22.715 inmigrantes ocupados en la agricultura en el 2002, a medida que arriban más recientemente al Paraguay, disminuyen su participación en el sector agrícola. Es cierto que tiene que ver con la propia disminución de la población inmigrante, pero aún así, si se considera la repartición actual por sector de actividad en función del año de llegada, se observa que los que llegaron en los años 1970 y 1980, se dedican del 31,9 \% hasta el 38,5\%, hoy a la agricultura. Al contrario, los que llegaron en los años inmediatos anteriores al Censo se dedican en el 2002, según el año de llegada, del 13,3\% y al 23,3\% a la agricultura. Paralelamente, se observa un aumento notable del empleo en los servicios.

Obviamente, hubiera sido mejor considerar la actividad del inmigrante en el momento de su llegada. Sin embargo, estas observaciones nos llevan a formular tres hipótesis. La primera hipótesis es que perdió importancia la producción agrícola en el espacio de la inmigración brasileña, lo cual, mecánicamente induce a una reducción de los empleos en el sector agrícola. La segunda, la agricultura no perdió su importancia, al contrario, sigue creciendo en producción y en sus impactos dinamizadores de otros sectores 
Folia Histórica del Nordeste, $\mathbf{N}^{\circ} 17$ (Resistencia, 2008) IIGHI, CONICET - IH, UNNE
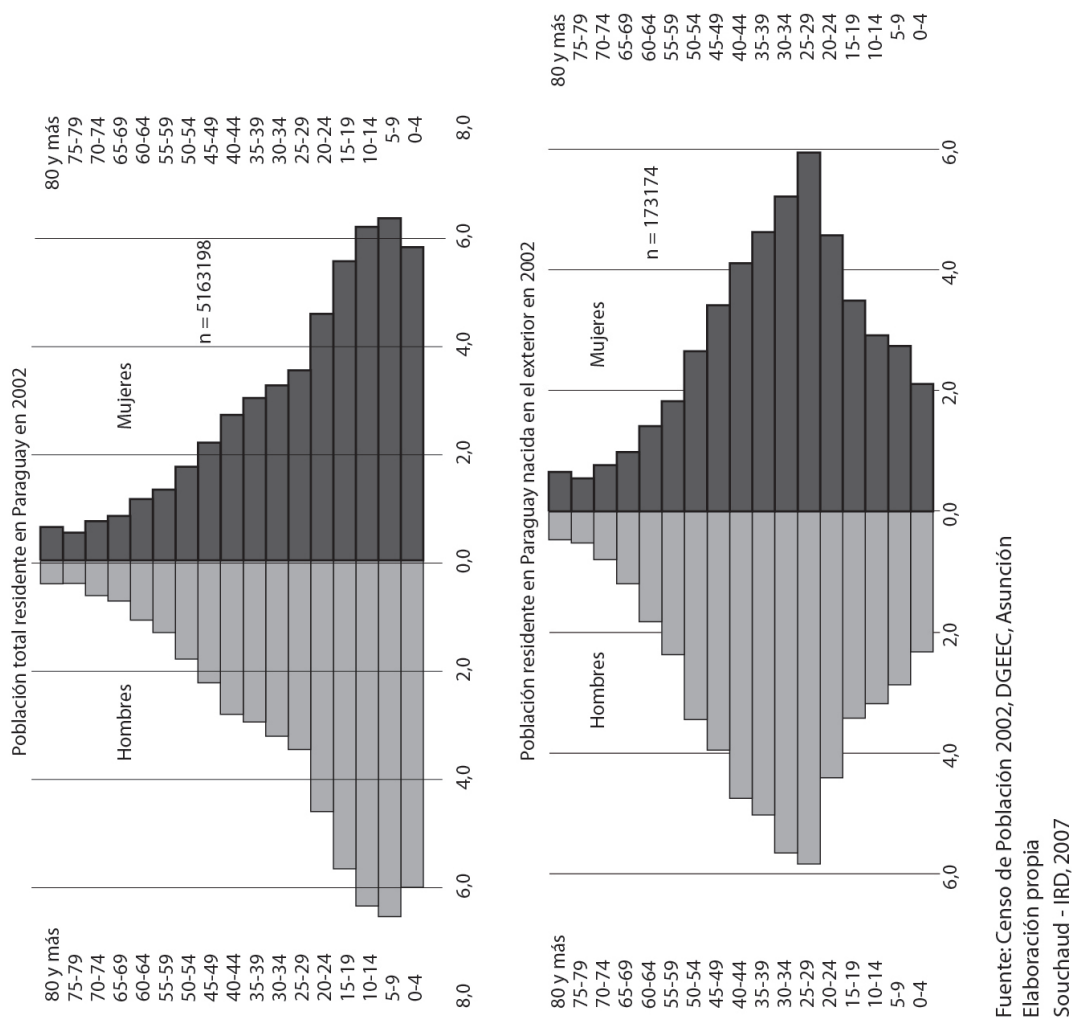

꾼

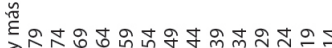

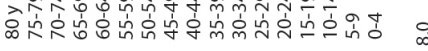

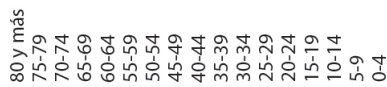
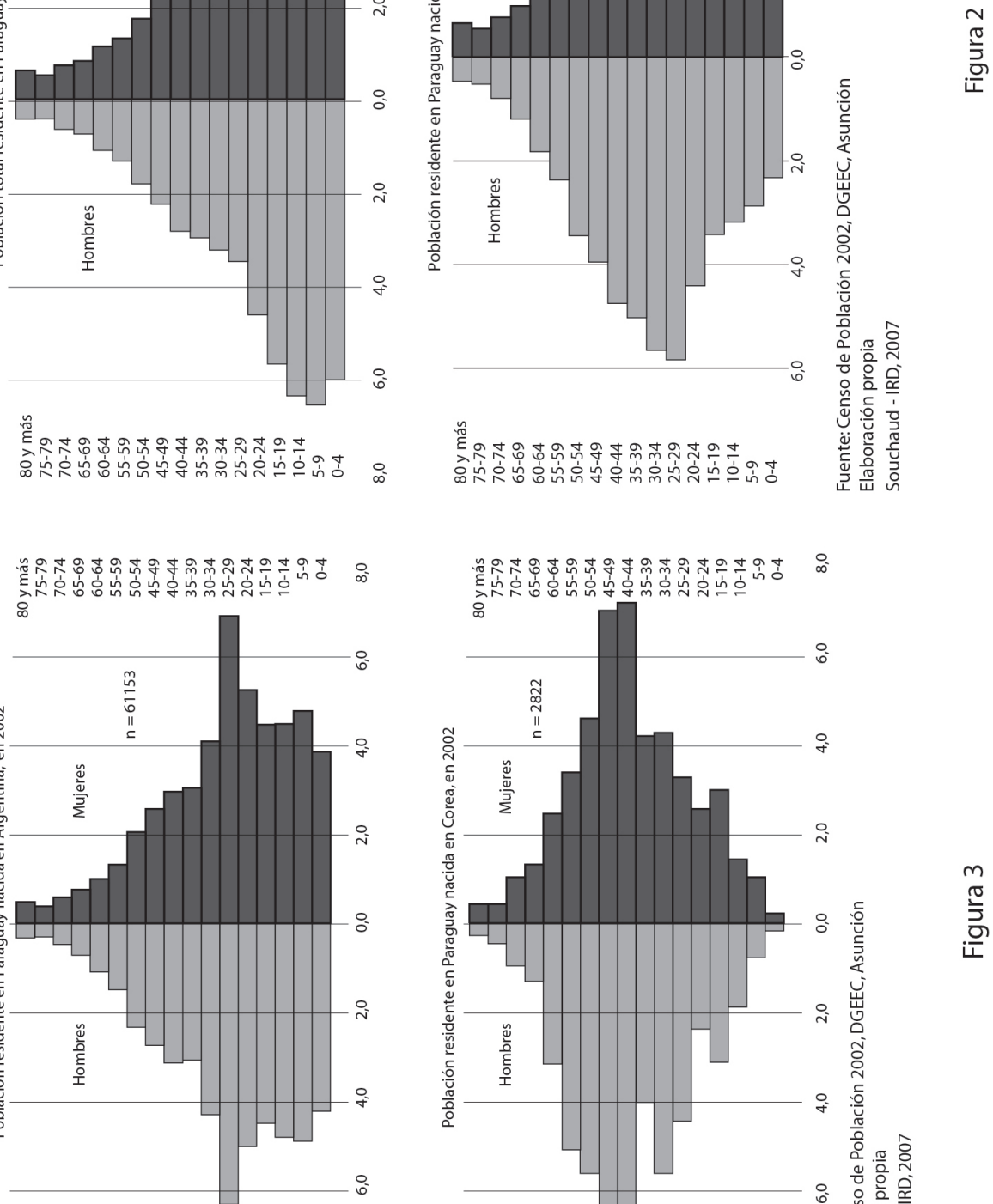

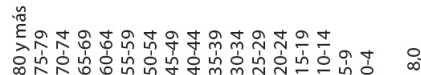

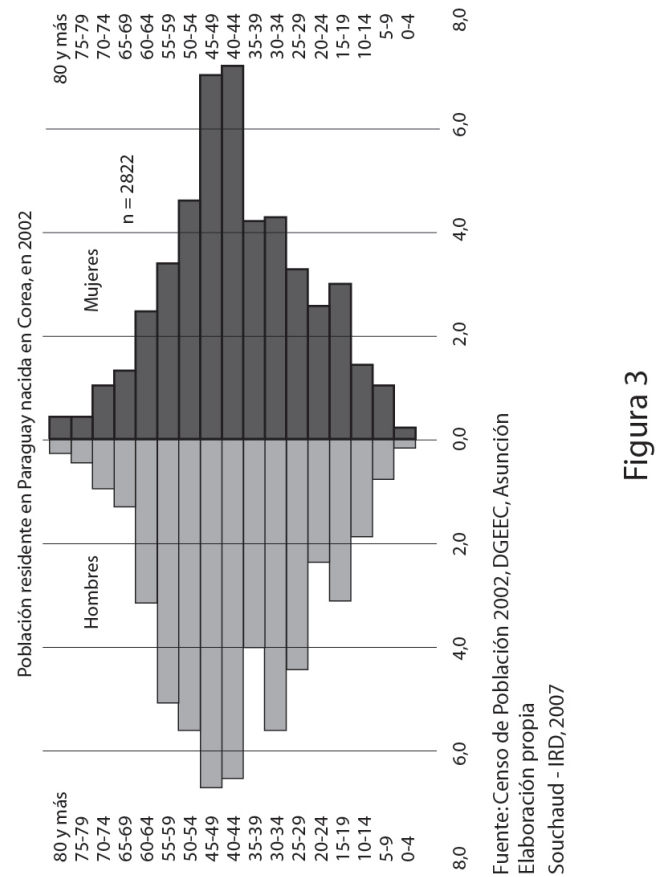



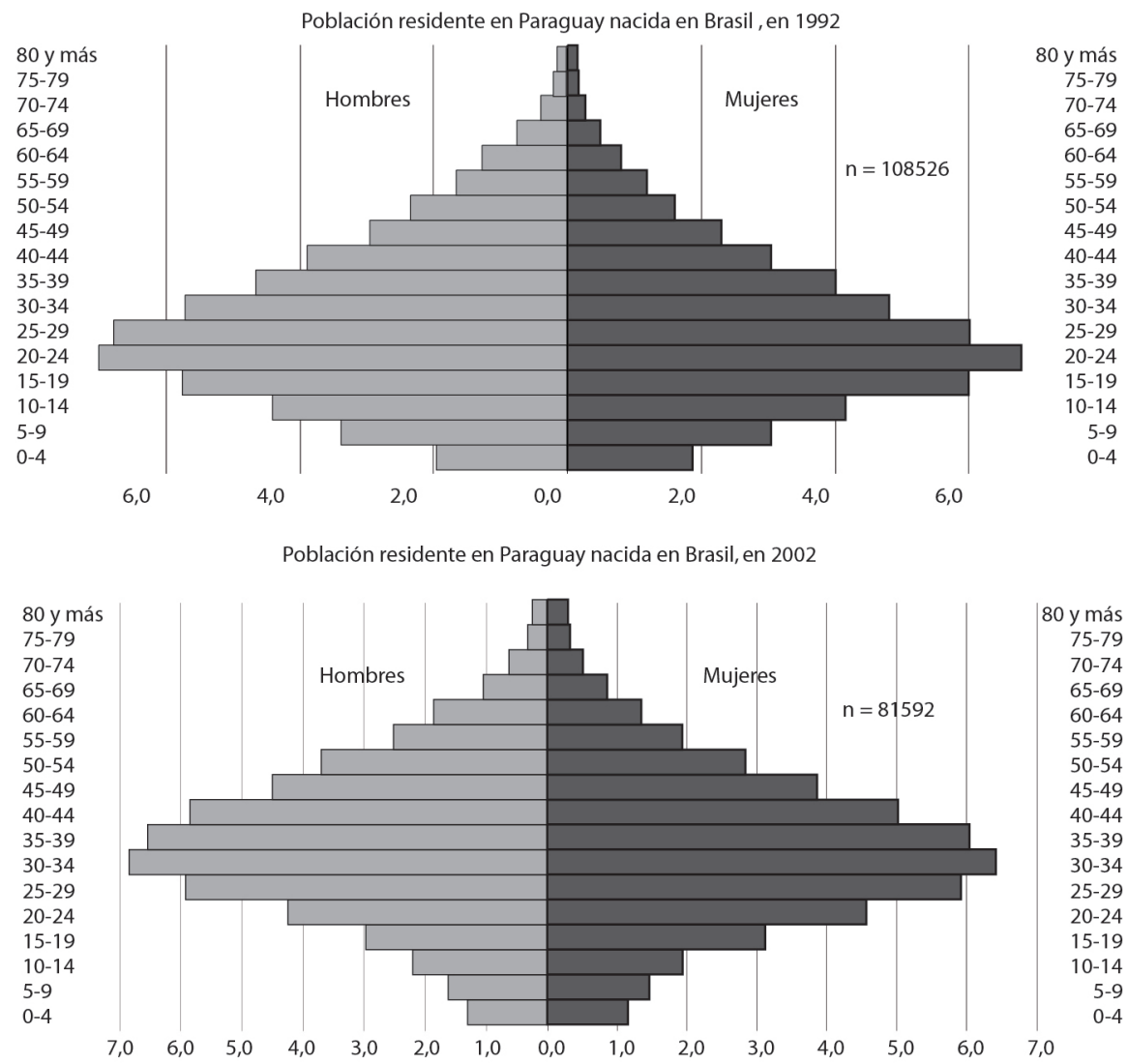

Fuente: Censos de Población 1992 y 2002, DGEEC, Asunción Elaboración propia

Souchaud - IRD, 2007

Figura 4

económicos, a pesar de una disminución del peso del sector agrícola en el paisaje laboral, pero gracias a una fuerte modernización del sector, la cual contribuye a la reducción del número absoluto de trabajadores empleados en el sector. Por último, aceptado el hecho de que sigue creciendo fuertemente el sector agrícola agro-exportador sojero, no podemos, al observar la disminución del número de los inmigrantes recién llegados ligados a esta actividad, descartar la posibilidad que la misma, fuertemente asociada históricamente a los inmigrantes brasileños, haya sido en parte transferida a la población no inmigrante, o sea paraguaya. Tomemos en cuenta en esta tercera hipótesis que los descendientes de brasileños, por el principio del "derecho del suelo" (jus solis) que se aplica en Paraguay, son en su gran mayoría, paraguayos. 


\section{Conclusión}

El Paraguay es hoy un país de primera importancia en los intercambios migratorios en América del Sur. Hemos querido mostrar en este texto algunos de los fundamentos de este fenómeno. Primero insistimos en el hecho que desde larga data, Paraguay asoció su desarrollo a una política de colonización agrícola cuyos actores principales serían inmigrantes internacionales. En un primer momento, obtuvo relativamente pocos resultados cuantitativos, sin embargo se registra en aquel momento poblaciones inmigrantes con orígenes diversificados que hasta hoy han sido importantes en la evolución social y espacial del país.

Después de la Segunda Guerra Mundial, Paraguay sigue este mismo objetivo pero, en relación con las profundas modificaciones en la dinámica migratoria mundial, por la cual se reducen de manera importante los flujos intercontinentales hacia América del Sur y se activan importantes flujos regionales, y específicamente entre países vecinos, consigue atraer una importante migración internacional.

En importancia, primero están los brasileños, después los argentinos, menos numerosos y que empiezan a llegar un poco después. Los dos colectivos representan la mayor parte del total de los inmigrantes y siguen esquemas de distribución no poco coincidentes. En el último censo tienden a equilibrarse numéricamente los dos contingentes. Con la pérdida de importancia de la inmigración brasileña se acentúa la tendencia a la urbanización de la inmigración internacional en Paraguay. La polarización de los centros urbanos sobre la inmigración no es reciente; la inmigración coreana demuestra lo contrario: desde su inicio en los años 1970 hasta ahora ha mantenido un padrón de ubicación casi exclusivamente metropolitano. Luego, la lectura espacial de estas tres migraciones tan distintas nos permite percibir la evolución reciente del Paraguay, país que está pasando de un patrón de sociedad marcado por lo agrario a un patrón más diversificado donde la ciudades asumen un papel creciente y donde lo agrícola (y ya no agrario, es decir agrícola y campesino) sigue importante. En esa transición no se dejó de integrar espacios marginales y no se marginalizaron los campos, al contrario, la dinámica de ocupación del espacio sigue siendo muy viva, pero quizás al igual que lo que se observó en otros lugares (Sur del oriente boliviano) los fenómenos de redistribución son acompañados por otros modelos territoriales de concentración (Domenach, Celton, Arze, y Hamelin 2007).

Por una parte, y como resultado de la superposición reciente de distintos flujos de inmigración internacional, Paraguay cuenta hoy con una gran diversidad de inmigrantes: migraciones de poblamiento, migraciones especializadas en sus actividades (algunas marcadas por su carácter empresarial), inmigración de mano de obra y de personal calificado, y probablemente, migraciones "étnicas" de retorno.

Por otra parte, las observaciones que hicimos llevan a otro tipo de interrogantes sobre la configuración actual y la evolución futura del Paraguay como país de inmigración. No podemos dejar de pensar que esta diversidad inmigratoria es muy reciente y poco consolidada. Así, notamos que la inmigración coreana conoció su auge en los años 1980, o sea más o menos 20 años atrás. Notamos también que la inmigración brasileña está 
disminuyendo: el stock bajó de más del 20\% entre los dos últimos censos ${ }^{7}$. Y la inmigración se mantiene a un nivel numérico (con ligera disminución, Tabla 1) casi estable por el crecimiento de la inmigración argentina. Sin embargo, es probable que esa inmigración sea en gran parte resultado de un proceso de retorno. Es decir que, de ser este el caso, la inmigración actual tendría sus fundamentos en la propia emigración. En otras palabras, Paraguay ya no tendría actualmente tanta capacidad de atracción para los inmigrantes internacionales; y si se mantiene esa tendencia en el futuro, se podría decir que el perfil de país de inmigración que empezó a conocer Paraguay en los últimos 30 años, correspondería a un paréntesis histórico, el cual, aunque breve, ha sido fundamental en la dinámica socioespacial del país en los últimos decenios.

\section{Bibliografía}

Bassanezi, Maria y Sílvia C. Beozzo. s.d. Migrações internacionais no Brasil: um panorama histórico. 39.

Causarano, Mabel. 2006. Dinámicas metropolitanas en Asunción, Ciudad del Este y Encarnación. Asunción: UNFPA/ADEPO

Celton, Dora. 1995. Plus d'un siècle d'immigration internationale en Argentine. Revue Européenne des Migrations Internationales 11: 145-165.

Cortêz, Cácia. 1993. Brasiguaios, os refugiados desconhecidos. São Paulo: Brasil Agora.

Domenach, Hervé, Dora Celton, Hugo Arze, y Philippe Hamelin (eds.). 2007 Movilidad y Procesos Migratorios en el Espacio de Frontera Argentino Boliviano. Córdoba: UNC.

Fischer, Sara, Tomás Palau, y Noemia Pérez. 1997. Inmigración y Emigración en el Paraguay 18701960. Asunción: BASE-IS/Clacso.

Palau Viladesau, Tomás y María Victoria Heikel. 1987. Los campesinos, el Estado y las empresas en la frontera agrícola. Asunción: Base/Pispal.

Pidoux de Drachenberg, Lyra. 1975. Inmigración y colonización en el Paraguay 1870-1970. Revista Paraguaya de Sociología 12: 65-123.

Souchaud, Sylvain. 2007. Geografía de la migración brasileña en Paraguay. Asunción: UNFPA ADEPO. Disponible en internet: http://www.brasil.ird.fr/article.php3?id_article=3034

Vázquez, Fabricio. 2006 Territorio y Población. Nuevas dinámicas regionales en el Paraguay. Asunción: UNFPA/ADEPO

Wagner, Carlos. 1990 Brasiguaios, homens sem pátria. Petrópolis: Vozes

\footnotetext{
${ }^{7}$ Siempre existe una duda sobre el valor a dar a los datos censales cuando se trata de inmigración. En el caso de la inmigración brasileña en Paraguay, parece que el Censo de 1992 sufrió mayor sub-registro que el de 2002. Hecho que refuerza la idea de una disminución del stock de brasileños entre los últimos dos censos de población.
} 


\title{
Resumen
}

En este texto se describen las características y la dinámica actuales de la inmigración internacional en Paraguay, insistiendo en las especificidades espaciales de los flujos que, en las últimas décadas, adquirieron mayor diversidad y complejidad. Después de una breve reseña de la historia inmigratoria del Paraguay, se estudia la distribución espacial y la actividad de los grupos de inmigrantes oriundos de Brasil, Argentina y Corea. Se intenta mostrar que los flujos migratorios son posibles indicadores de los importantes cambios que está conociendo el país en cuanto a sus formas de ocupación del espacio y en la definición de nuevos marcos en las relaciones sociales.

$$
<\text { Paraguay }><\text { Migración internacional }><\text { Inmigración }>
$$

\begin{abstract}
This paper presents some of the characteristics and present dynamic of international inmigration in Paraguay, focusing on the spatial specificities of those migration flows that, in the last decades, reached a major diversity and complexity. After a short review of migration history in Paraguay, we analyze the geographic distribution, the occupational and the age structure of migrant population coming from Brazil, Argentina and Korea. We are trying to prove that migratory flows illustrate about some important changes that Paraguay produces in relation to occupation of space and construction of new social relationships frames.
\end{abstract}

$<$ Paraguay $><$ International migration $><$ In-migration $>$ 